\title{
Hydrography of the eastern Arabian Sea during summer monsoon 2002
}

\author{
D Shankar ${ }^{1 *}$, S S C Shenoi ${ }^{1}, \mathrm{R}$ K NAYAK ${ }^{1}, \mathrm{P}$ N VinayaChandran ${ }^{2}$, G Nampoothiri ${ }^{1}$, \\ A M Almeida ${ }^{1}$, G S Michael ${ }^{1}$, M R Ramesh Kumar ${ }^{1}$, D Sundar ${ }^{1}$, and O P Sreejith ${ }^{1}$ \\ ${ }^{1}$ National Institute of Oceanography, Dona Paula, Goa 403004 , India. \\ ${ }^{2}$ Indian Institute of Science, Bangalore 560 012, India. \\ *e-mail: shankar@darya.nio.org
}

Hydrographic observations in the eastern Arabian Sea (EAS) during summer monsoon 2002 (during the first phase of the Arabian Sea Monsoon Experiment (ARMEX)) include two approximately fortnight-long CTD time series. A barrier layer was observed occasionally during the two time series. These ephemeral barrier layers were caused by in situ rainfall, and by advection of low-salinity (high-salinity) waters at the surface (below the surface mixed layer). These barrier layers were advected away from the source region by the West India Coastal Current and had no discernible effect on the sea surface temperature. The three high-salinity water masses, the Arabian Sea High Salinity Water (ASHSW), Persian Gulf Water (PGW), and Red Sea Water (RSW), and the Arabian Sea Salinity Minimum also exhibited intermittency: they appeared and disappeared during the time series. The concentration of the ASHSW, PGW, and RSW decreased equatorward, and that of the RSW also decreased offshore. The observations suggest that the RSW is advected equatorward along the continental slope off the Indian west coast.

\section{Introduction}

In this paper, we describe the hydrographic observations carried out in the eastern Arabian Sea (EAS) during two cruises conducted on board $O R V$ Sagar Kanya in the summer monsoon of 2002 as part of the first phase of the Arabian Sea Monsoon Experiment (ARMEX) (Anonymous 2001, 2002). The cruise tracks are shown in figure 1 . The observations include a few sections and two CTD (Conductivity-Temperature-Depth) time series of about a fortnight each.

A total of 378 profiles of temperature and salinity were collected using a SeaBird SBE 9/11Plus CTD; see table 1 for a summary of the observations. The first cruise, SK-178, was during 21st June to 15th July 2002 (25 days) and the second, SK-179, was during 17th July to 16th August (31 days). We first describe the general hydrography, as seen in the sections and time series (section 2); we then describe the surface layer in greater detail in section 3 and the water masses in section 4 . Section 5 summarises the paper.

\section{Hydrography}

\subsection{Sections}

One cross-shore section off Goa (section G, $\sim 15^{\circ} \mathrm{N}$ ) was covered during both cruises (figure 1 , table 1); it was chosen because it has been sampled several times during the last decade. Two alongshore sections were covered during SK-179; section $\mathrm{A}$ was covered at the beginning of the cruise and section $\mathrm{B}$ at the end.

During both cruises, upwelling was evident on the shelf and slope in vertical sections of temperature and salinity along section G (figures 2 and 3). As in climatology (Levitus and Boyer 1994), the upwelling increased from June to August. During

Keywords. Barrier layer; time series; Red Sea Water; Persian Gulf Water; water masses. 


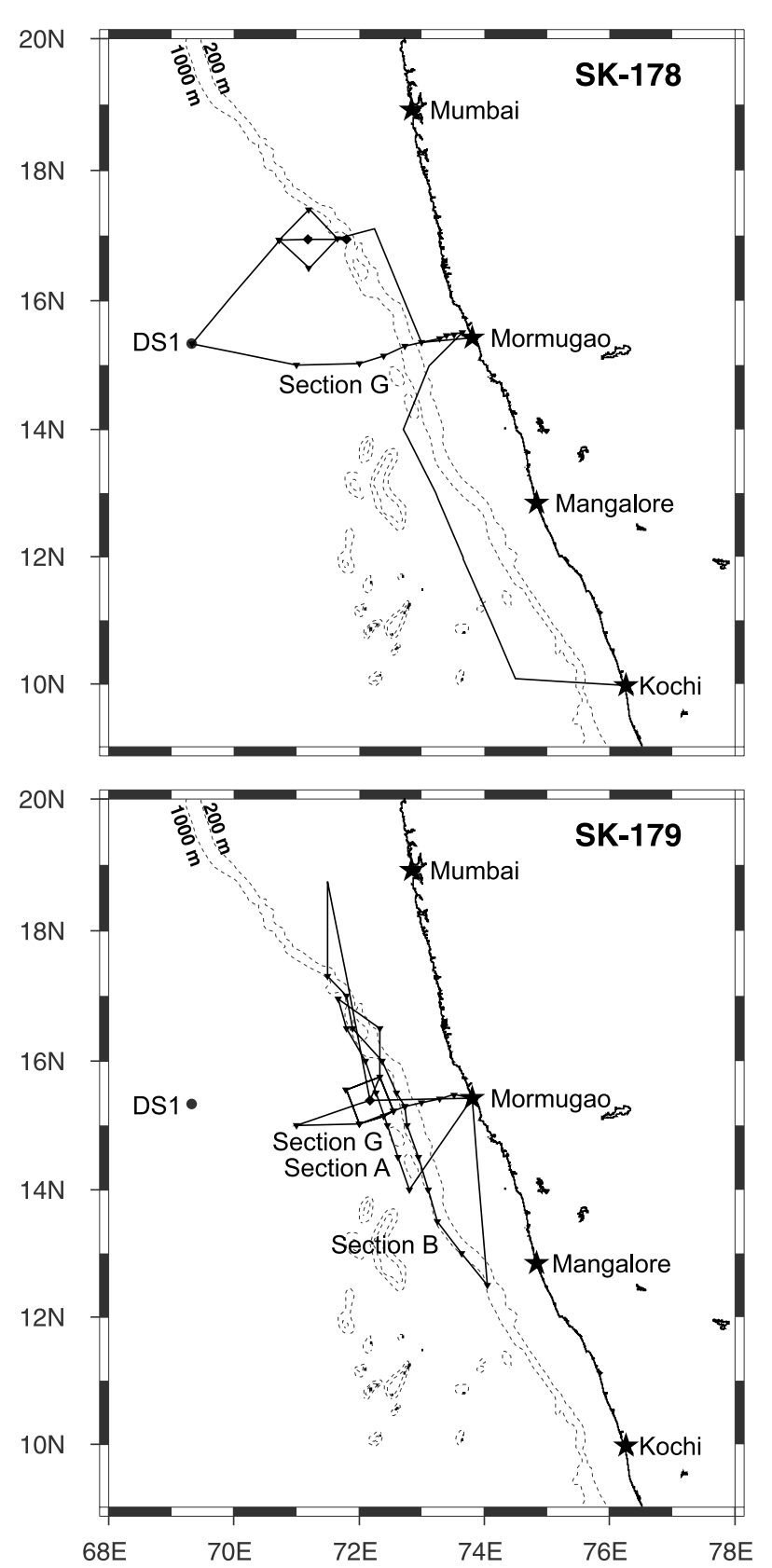

Figure 1. Cruise tracks for SK-178 (top) and SK-179 (bottom). The ports of embarkation and disembarkation for SK-178 (SK-179) were Kochi (Mormugao) and Mormugao (Mormugao). DS1 marks the location of a moored buoy deployed by the National Institute of Ocean Technology, India. For both cruises, the CTD stations along sections and on the squares are marked by inverted triangles and the time-series location (TSL) by diamonds. During SK-178, the TSL was shifted closer to shore on 10th July 2002, and both TSLs are marked on the track. On both cruises, the squares were covered before and after the time-series measurements. See table 1 for the chronology.

SK-178, in early June, there were signatures of downwelling below $120 \mathrm{~m}$, implying the existence of an undercurrent, as has been reported earlier too (Banse 1958; Shetye et al 1990; Antony 1990; Stramma et al 1996); during SK-179, in early August, the downwelling signature was absent.
During SK-178, in early June (figure 2), the surface mixed layer was $40 \mathrm{~m}$ deep uniformly across section G (except in the vicinity of the coast), the sea surface temperature (SST) exceeded $28^{\circ} \mathrm{C}$, the surface salinity was below 36 PSU and fell to 34 PSU at the station nearest the coast. These values are comparable with the climatology (Levitus and Boyer 1994; Levitus et al 1994). The salinity below the mixed layer, however, exceeded the climatological value by almost 0.5 PSU. By early August, during SK-179 (figure 3), the surface mixed layer off the shelf had deepened to $60 \mathrm{~m}$ owing to the monsoon winds. The SST, however, still exceeded $28^{\circ} \mathrm{C}$, about $1^{\circ} \mathrm{C}$ higher than in the climatology of Levitus and Boyer (1994) and $0.5^{\circ} \mathrm{C}$ higher than in a climatology constructed from the weekly data of Reynolds and Smith (1994). This was owing to the weak summer monsoon in 2002 , which turned out to be one of the worst droughts recorded in India, with a deficit of $49 \%$ during the summer monsoon peak in July (Gadgil et al 2002; Kalsi et al 2004); the winds were also weaker during 2002 July, leading to lower evaporation and higher SST (Vinayachandran 2004). Surface salinity had increased since June, low-salinity waters $(\sim 34.8$ PSU) being restricted to the shelf. The increase in salinity was also seen between 120 and $600 \mathrm{~m}$, the regime of the undercurrent. The likely reason for the increase in salinity is an inflow of waters of higher salinity from the north along the coast.

Upwelling increased equatorward along the coast in section B during SK-179 (figure 4); this section followed roughly the $800 \mathrm{~m}$ isobath. The equatorward increase in upwelling, which has been noted earlier (Banse 1968; Johanessen et al 1981; Shetye et al 1990), results in a shallower surface mixed layer in the south $(\sim 20 \mathrm{~m})$ than in the north $(\sim 50-60 \mathrm{~m})$. This upwelling gradient occurs because upwelling starts in the south along the Indian west coast and progressively shifts to the north (Sharma 1968; McCreary et al 1993; Shankar and Shetye 1997). The salinity in section $\mathrm{B}$ decreased rapidly south of $13^{\circ} \mathrm{N}$, as also happened in an alongshore section covered during another ARMEX cruise during June 2003 (Shenoi et al 2005a, b), suggesting a salinity front near this latitude owing to the entrapment of the lowsalinity waters in the Lakshadweep High and Low (Bruce et al 1994; Shankar and Shetye 1997; Han and McCreary 2001). Below $200 \mathrm{~m}$ too, salinity increased poleward and the high-salinity patch at $500 \mathrm{~m}$ (which corresponds to $27 \sigma_{t}$ ) north of $15^{\circ} \mathrm{N}$ is a clear sign of Red Sea Water (RSW). The salinity bulges suggest an equatorward surface current, with a poleward undercurrent below in the depth range $\sim 100-200 \mathrm{~m}$. Below this, the equatorward bulge in the regime of RSW suggests 
Table 1. Summary of the two cruises. $N$ is the number of CTD profiles. In each cruise, a square was traced around the time-series location, with CTD casts made at the vertices. The CTD casts tabulated above, those at the vertices of the squares, and a few other CTD profiles make the total of 160 profiles during SK-178 and 218 during SK-179. In both cruises, section $G$ was covered from east-west. During SK-179, section A was covered south-north and section B north-south.

\begin{tabular}{llrcc}
\hline Cruise & Segment & $N$ & Start time (UTC) & End time (UTC) \\
\hline SK-178 & Section G & 9 & 24th June, 1245 & 26th June, 1300 \\
& Time series 1 & 120 & 29th June, 2315 & 10th July, 1530 \\
& Time series 2 & 20 & 10th July, 2000 & 13th July, 1130 \\
\hline \multirow{2}{*}{ SK-179 } & Section A & 8 & 18th July, 0240 & 20th July, 0230 \\
& Time series & 169 & 21st July, 1530 & 5th August, 0630 \\
& Section G & 8 & 5th August, 2200 & 9th August, 0945 \\
& Section B & 12 & 12th August, 0345 & 14th August, 2205 \\
\hline
\end{tabular}

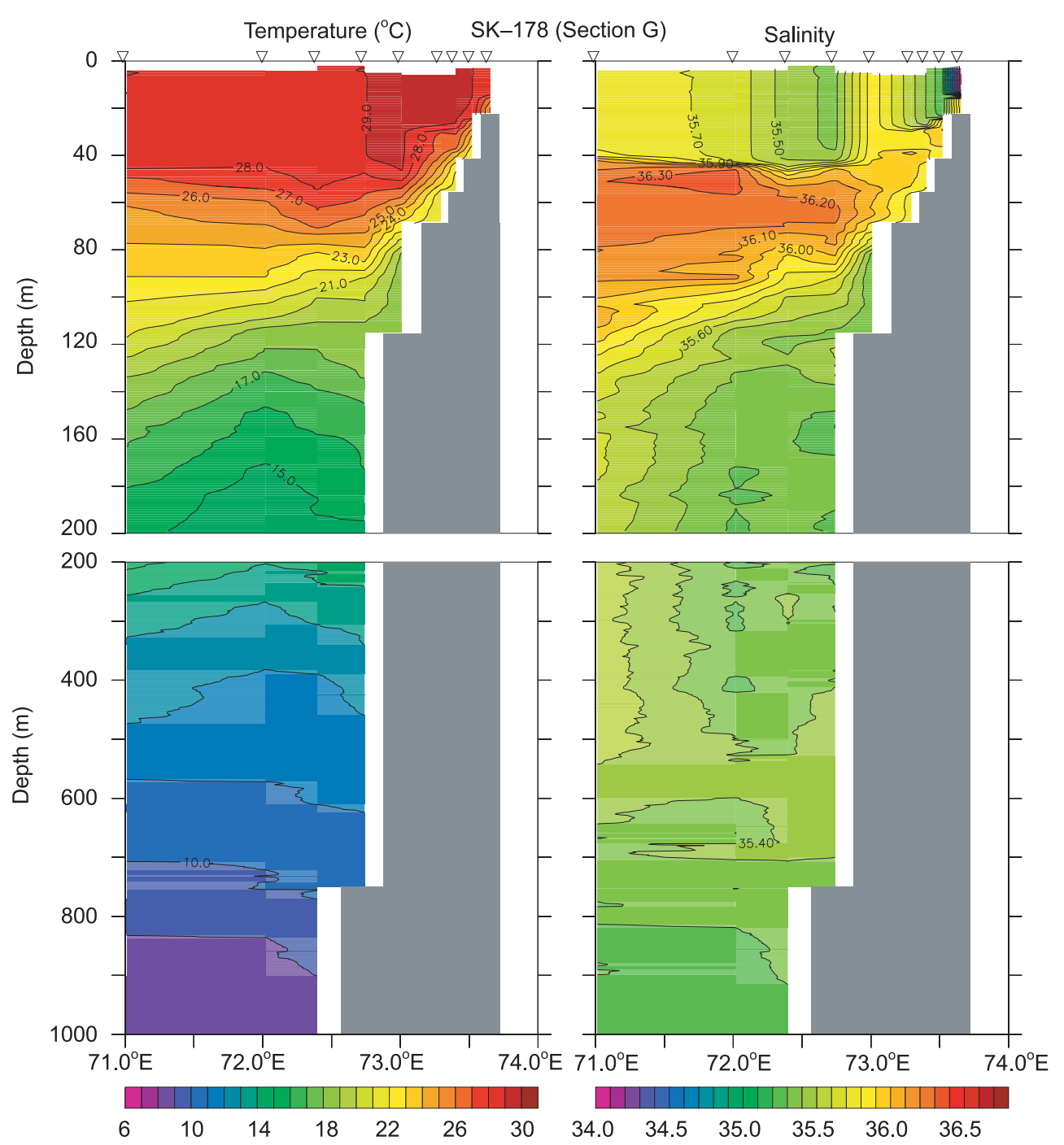

Figure 2. Temperature (left, ${ }^{\circ} \mathrm{C}$ ) and salinity (right, PSU) along section G (off Goa, $\sim 15^{\circ} \mathrm{N}$ ) during SK-178 (24th-26th June 2002). Contour intervals are $1^{\circ} \mathrm{C}$ and 0.1 PSU. The inverted triangles on the top mark the station locations.

on equatorward flow again. Such salinity bulges suggesting an equatorward surface current and poleward undercurrent were also observed during the summer monsoon of 1987 (Shetye et al 1990, their figure 9 ).

\subsection{Time series}

Two time series, at TSL1 $\left(16^{\circ} 56.6^{\prime} \mathrm{N}, 71^{\circ} 11.2^{\prime} \mathrm{E}\right.$, 30 th June to 10th July, water depth $2250 \mathrm{~m}$ ) and TSL2 $\left(16^{\circ} 56.7^{\prime} \mathrm{N}, 71^{\circ} 48^{\prime} \mathrm{E}, 10 \mathrm{th}-12\right.$ th July, 

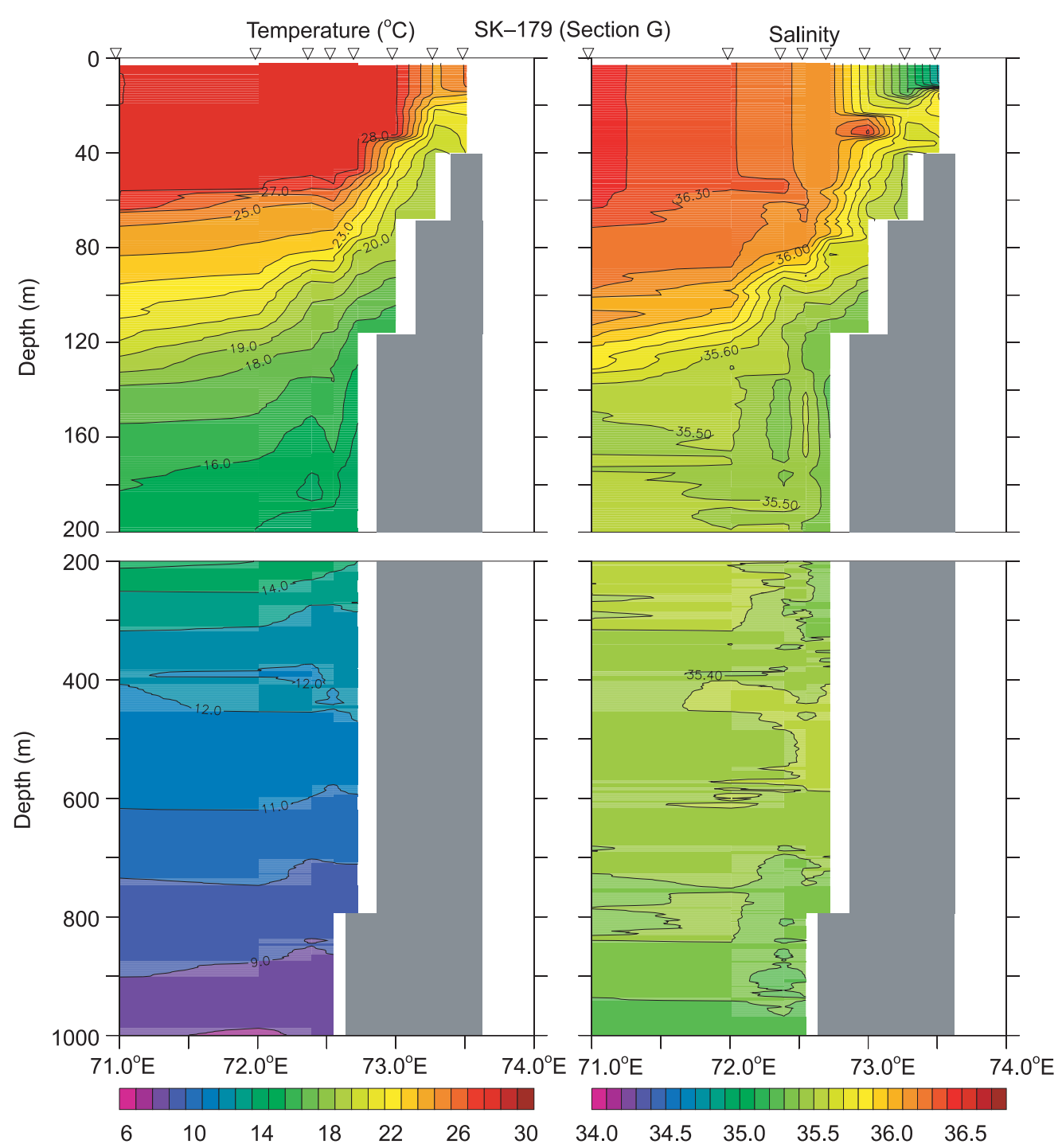

Figure 3. Temperature (left, ${ }^{\circ} \mathrm{C}$ ) and salinity (right, PSU) along section G (off Goa, $\sim 15^{\circ} \mathrm{N}$ ) during SK-179 (5th-9th August 2002). Contour intervals are $1^{\circ} \mathrm{C}$ and 0.1 PSU. The inverted triangles on the top mark the station locations.

water depth $1180 \mathrm{~m})$, were covered during SK-178 (figure 1). (TSL is used hereafter when referring to the time-series locations, use of TSL1 and TSL2 being restricted to cases specific to the two TSLs.) The time series consisted of a CTD cast to $1000 \mathrm{~m}$ depth once every two hours (figure 5) after occupying four stations at the corners of the squares (see figure 1); these four casts were also repeated at the end of the time series. Most striking are the internal tides (semi-diurnal and diurnal) and the intermittent patches of low and high salinities over the entire depth range. The edges of these patches appear vertical in the time-depth plot, implying that they are due to advection. The surface mixed layer was $\sim 50 \mathrm{~m}$ deep, comparable to that in section $\mathrm{G}$. The time series started about 6 days after the stations near the coast were sampled during the section. This time lag, and the location of TSL1 being almost $2^{\circ}$ north of the section presumably were the causes of the higher surface salinity at the TSL. The salinity was below 36 PSU at the start of the time series, but increased by over 0.5 PSU by 6 th July. The likely cause of the low salinities early during the period is the heavy rainfall that occurred along the Indian west coast and the adjoining EAS in the week preceding the cruise (figure 6); this included two Intense Rainfall Events (IREs) during 14th-16th and 20th22nd June (Mohanty et al 2002). Salinity varied in space too, decreasing by 0.3 PSU when the ship moved $\sim 70 \mathrm{~km}$ inshore to TSL2. The low surface salinity at TSL2 is broken by a high-salinity spike for a few hours during 11th July, suggesting that the equatorward WICC, which normally advects high-salinity waters from the north (Shetye et al 1990; Shenoi et al 2004), was also advecting patches of low-salinity pools that formed as a result of the rain events and the subsequent mixing and 


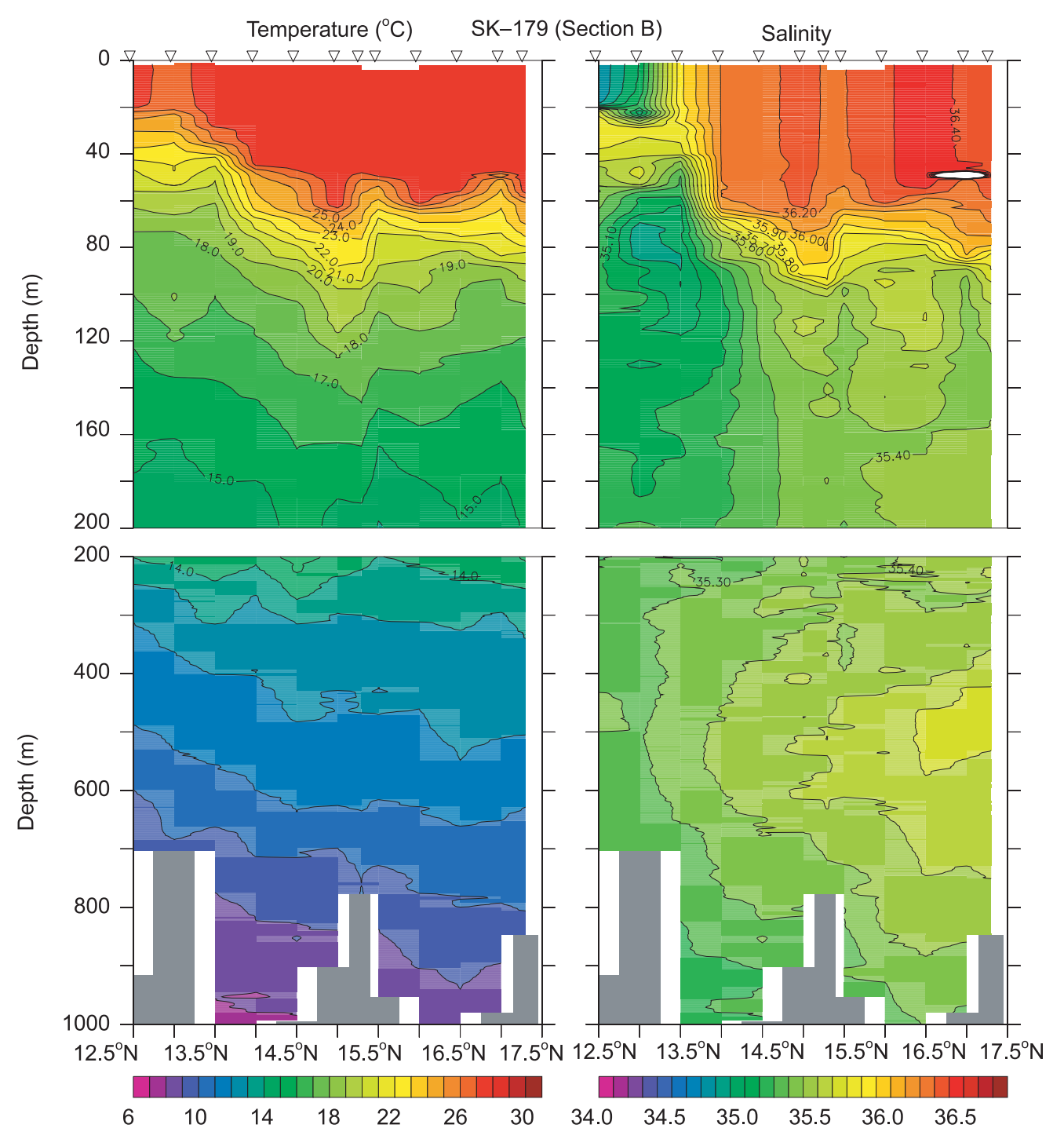

Figure 4. Temperature (left, ${ }^{\circ} \mathrm{C}$ ) and salinity (right, PSU) along section B (alongshore section) during SK-179 (12th-14th August 2002). Contour intervals are $1^{\circ} \mathrm{C}$ and $0.1 \mathrm{PSU}$. The inverted triangles on the top mark the station locations.

disintegration of the freshwater pools by the currents. At greater depths too, there was a difference in salinity between the two TSLs. Salinity was higher nearer the coast at $500 \mathrm{~m}\left(\sigma_{t} \sim 27 \mathrm{~kg} \mathrm{~m}^{-3}\right)$, the regime of the RSW.

The time series during SK-179 was during 21st July to 5th August at $72^{\circ} 10.23^{\prime} \mathrm{N}, 15^{\circ} 23.07^{\prime} \mathrm{E}$ (figure 1). The location was chosen to lie close to section G on the continental slope (water depth $1950 \mathrm{~m}$ ). As during SK-178, the time series consisted of a CTD cast to $1000 \mathrm{~m}$ depth once every two hours; during the first 24 hours (21st-22nd July), however, casts were made every 3 hours to $1800 \mathrm{~m}$. The internal tides seen at the SK-178 TSL were evident at the SK-179 TSL too (figure 7). There was hardly any change in SST, but the surface high-salinity layer was punctuated by bursts of low-salinity waters. A sharp drop of over 0.7 PSU occurred within 6 hours on 3rd August owing to a moderate rain event off Goa (figure 6), but the salinity recovered within 10 hours; the surface salinity dropped again towards the end of the time series. (We show in section 3 that the in situ rainfall could not have caused such a large change in salinity.) By the time the ship returned to the vicinity of the TSL on 7th August while covering section $G$, the salinity had recovered to its normal value (see salinity for sixth and seventh stations from the coast in figure 3). Below the surface high-salinity layer were low-salinity waters advected from the south (figure 4). The interface between these two waters deepened from 60 to $100 \mathrm{~m}$ around 28th July. Around this time, the thin high-salinity bands around the 26.4 (core of Persian Gulf Water, PGW) and $27 \sigma_{t}$, which were separated during the first half of the time series by a salinity minimum (Shenoi et al 1993; Shetye et al 1994), merged rapidly to form a single high-salinity 


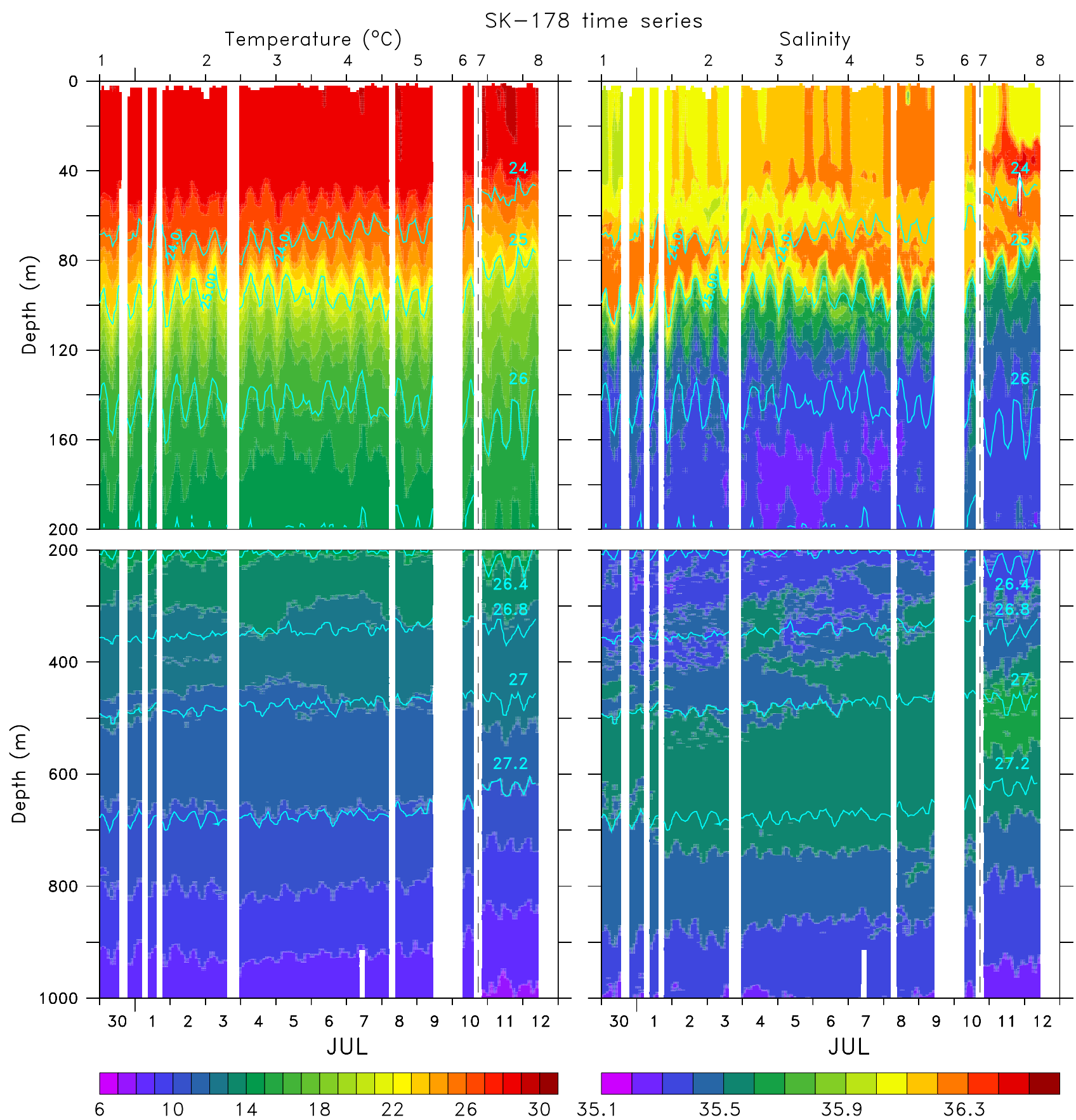

Figure 5. Temperature (left, ${ }^{\circ} \mathrm{C}$ ) and salinity (right, PSU) during the time series in SK-178. The time series was started at $16^{\circ} 56.6^{\prime} \mathrm{N}, 71^{\circ} 11.2^{\prime} \mathrm{E}$ on 30 th June and a CTD cast was made once every two hours till 10th July; the breaks (white space) seen in the data are a result of casts being missed owing to CTD or winch failure. The location of the time series was shifted about $70 \mathrm{~km}$ closer to the coast $\left(16^{\circ} 56.7^{\prime} \mathrm{N}, 71^{\circ} 48^{\prime} \mathrm{E}\right)$ on 10 th July; this location was occupied till 13 th July. Contour intervals are $1^{\circ} \mathrm{C}$ and $0.1 \mathrm{PSU}$ and the contours (cyan) are for $\sigma_{t}\left(\mathrm{~kg} \mathrm{~m}^{-3}\right)$. The vertical dashed line separates these two time series during SK-178. The numbers on the top of the panels mark the CTD casts selected for the TS-diagram in figure 11 .

layer almost $400 \mathrm{~m}$ thick $(\sim 160-600 \mathrm{~m})$, and the salinity minimum disappeared. Shenoi et al (1993) called this the Arabian Sea Water (ASW). Simultaneously, low-salinity waters which were present between 900 and $1000 \mathrm{~m}$ till 25th July, disappeared thereafter for over 3 days, but reappeared between 800 and $1000 \mathrm{~m}$ on 30th July. The coherence in the changes over such a large depth range suggests that advection is the cause of the disappearance of the salinity minimum between the PGW and the RSW, and that there was a change in the direction of the undercurrent. (CTD time-series measurements on the continental shelf off Kochi during May-June 1992 showed similar changes in 


\begin{tabular}{lllll|l|l|l|l|l|}
\hline & & & & & & & & & \\
0 & 1 & 2 & 4 & 6 & 8 & 10 & 12 & 20
\end{tabular}
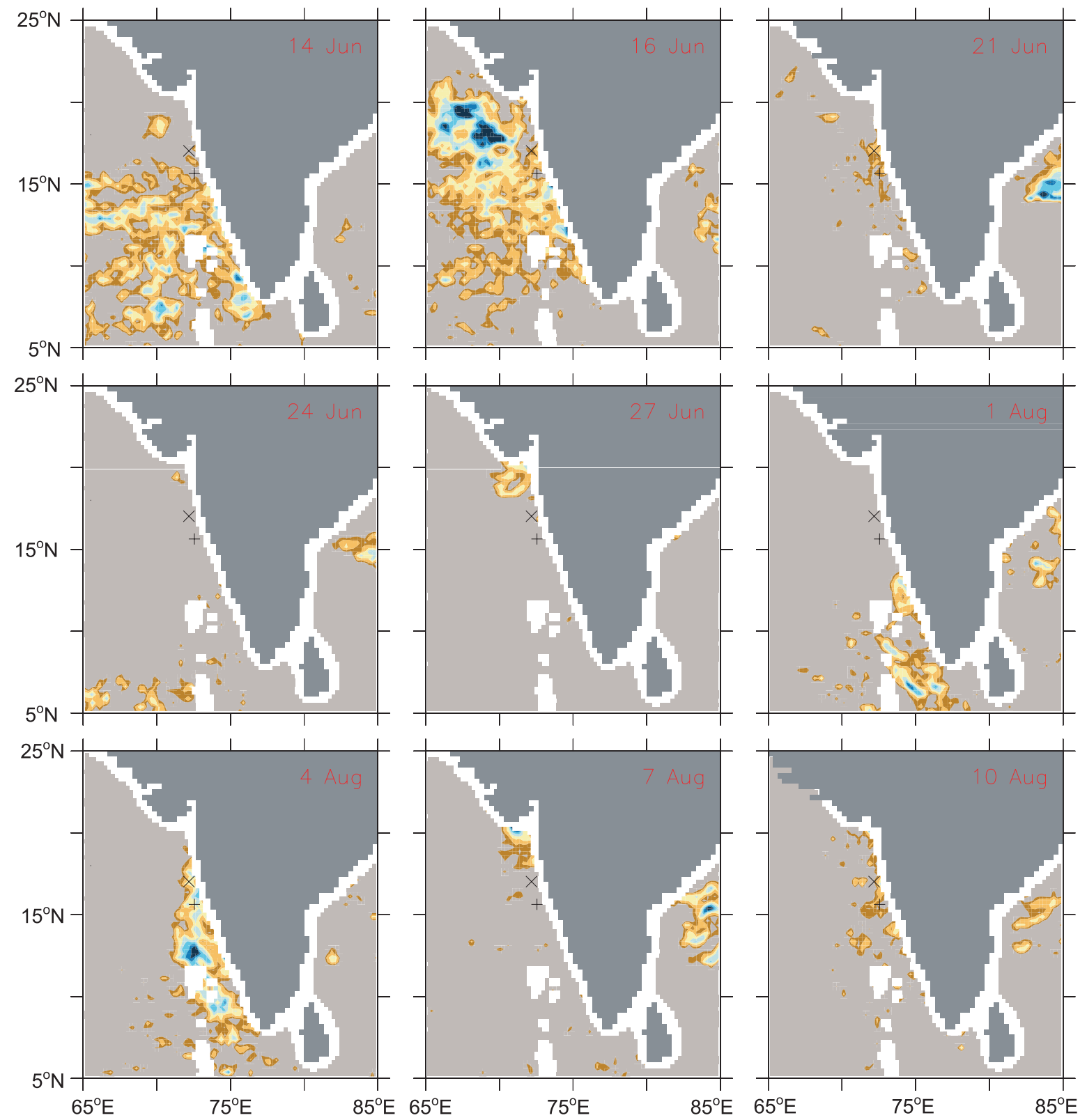

Figure 6. Rainfall (mm/hour) from TMI (TRMM Microwave Imager) during the two cruises. The cross (plus) marks the TSL during SK-178 (SK-179). There were three Intense Rainfall Events (IREs) during SK-178. (During the summer monsoon, there are days on which rainfall at a meteorological station on the west coast exceeds $12 \mathrm{~cm}$. Such bursts of heavy rainfall are called IREs by the India Meteorological Department (Anonymous 2001).) The first IRE was on the southern half of the west coast during 14 th-16th June. The second IRE, during 20 th-22nd June, was weaker and was felt more in the middle of the west coast; this IRE does not appear strongly in the satellite data over the EAS. The third IRE was mostly over Gujarat (northwest India) during 26th-28th June, and the rainfall did not extend far into the EAS in the satellite data. This event, however, was the strongest, with IREs being recorded at several meteorological stations in Gujarat on each of the 3 days; at some stations, rainfall exceeded $40 \mathrm{~cm}$ over 24 hours. There were two moderate rainfall events and one IRE during SK-179. The first moderate rainfall event was in Goa on 16th July; this event was probably restricted to land and is not seen in the satellite data. The second such event was more widespread and propagated northward along the coast during 1st-4th August. The IRE was recorded during 7th-10th August and rainfall was particularly heavy near Mumbai. (All descriptions of the IREs are based on Mohanty et al (2002).)

salinity - appearance and disappearance of lowsalinity blobs - that coincided with reversals in the current (Hareeshkumar et al 1995)).
The SK-178 time series is too short $(\sim 256$ hours $)$ for an analysis of the internal tides. An analysis of the SK-179 time series, however, is possible 


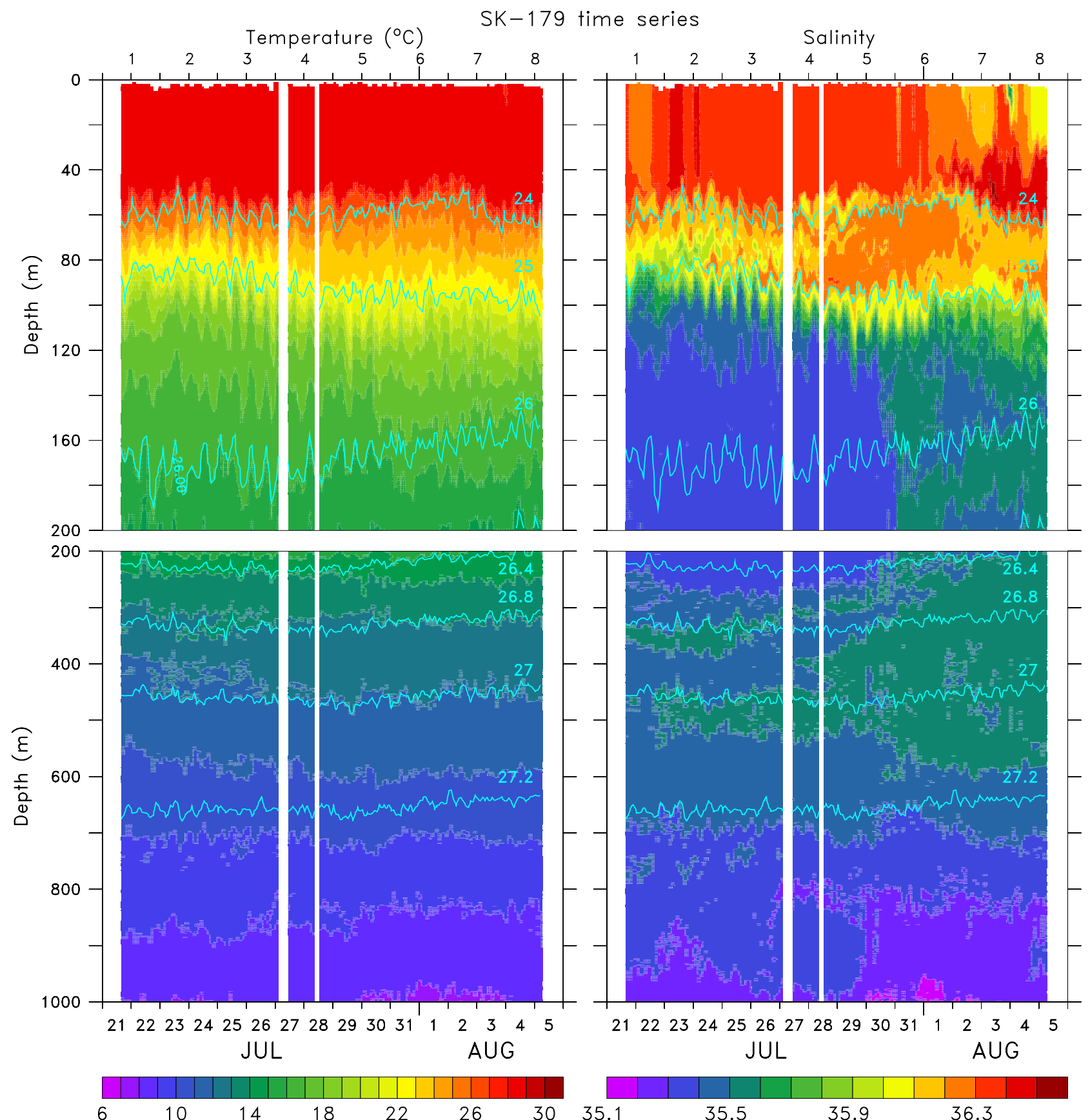

Figure 7. Temperature (left, ${ }^{\circ} \mathrm{C}$ ) and salinity (right, PSU) during the time series in SK-179. The time-series measurements were made during 21st July to 5th August at $72^{\circ} 10.23^{\prime} \mathrm{N}, 15^{\circ} 23.07^{\prime} \mathrm{E}$. A CTD cast was made every 3 hours for the first 24 hours (21st-22nd July), and once every 2 hours thereafter. The breaks (white space) seen in the data are a result of casts being missed owing to CTD or winch failure. Contour intervals are $1^{\circ} \mathrm{C}$ and $0.1 \mathrm{PSU}$ and the contours (cyan) are for $\sigma_{t}$ $\left(\mathrm{kg} \mathrm{m}^{-3}\right)$. The numbers on the top of the panels mark the CTD casts selected for the TS-diagram in figure 11.

as the record length is 349 hours, comparable to the length required to separate the semi-diurnal components $\mathrm{M}_{2}$ and $\mathrm{S}_{2}$ (355 hours) (Foreman 1977). The harmonic analysis for the temperature field (Anonymous 1996) (figure 8) shows that the amplitude of the semi-diurnal components $\mathrm{M}_{2}$ and $\mathrm{S}_{2}$ was about $0.5^{\circ} \mathrm{C}$ and $0.45^{\circ} \mathrm{C}$ at $100 \mathrm{~m}$. The amplitude of the $\mathrm{O}_{1}$ diurnal component was $0.35^{\circ} \mathrm{C}$; that of $\mathrm{K}_{1}$ was much less. Though a more rigorous analysis of the internal tides is beyond the scope of this paper, it is worth noting that they contribute to an error of $4-6$ dyn-cm at the two TSLs (figure 9). This is comparable to the 0/1000 dynamic-height difference across section G (considering only stations deeper than $1000 \mathrm{~m}$ ), implying a signal-to-noise ratio of $\sim 1$; hence, geostrophic computations have not been shown for the sections. 


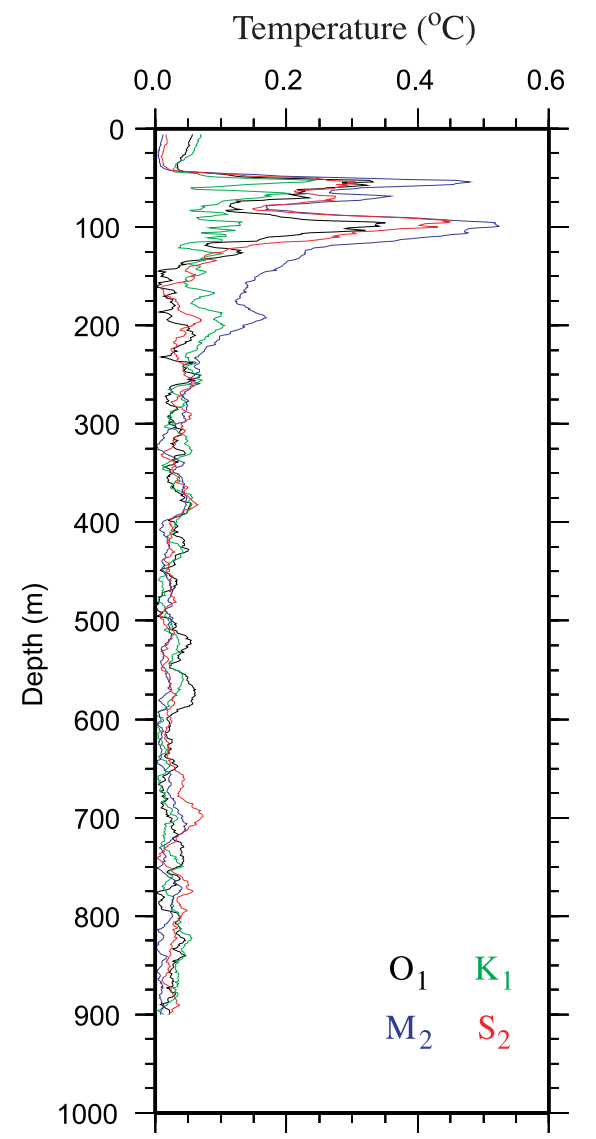

Figure 8. Semi-diurnal $\left(\mathrm{M}_{2}\right.$ and $\left.\mathrm{S}_{2}\right)$ and diurnal $\left(\mathrm{O}_{1}\right.$ and $\mathrm{K}_{1}$ ) components of the temperature $\left({ }^{\circ} \mathrm{C}\right)$ field for the SK-179 time series.

\section{Ephemeral barrier layers}

During both cruises, the depth of the mixed layer, defined on the basis of density (depth at which density exceeds surface density by the density equivalent to $1^{\circ} \mathrm{C}$ increase in temperature) (Shenoi et al 2004), and the depth of the isothermal layer (depth at which temperature exceeds $\mathrm{SST}$ by $1^{\circ} \mathrm{C}$ ) were almost the same. Hence, for most of the duration of the time series, there was no barrier layer (figure 10), as in the climatology of the region (Rao and Sivakumar 2003). (Barrier layer is the part of the isothermal layer below the mixed layer.) On a few occasions, however, a barrier layer did form, but was ephemeral.

The salinity over the top $40 \mathrm{~m}$ increased almost continuously at $\sim 0.02 \mathrm{PSU}$ day $^{-1}$ during 30 th June-9th July at the SK-178 TSL (figure 10). This increase was, however, punctuated by a sharp decrease in the near-surface salinity (top $10 \mathrm{~m}$ ) for a few hours during 8th July, leading to a short-lived barrier layer. The salinity below $20 \mathrm{~m}$ increased by over $0.2 \mathrm{PSU}$ when the ship moved shorewards from TSL1 to TSL2 on 10th July, but the salinity in the top $20 \mathrm{~m}$ decreased by 0.2 PSU. Since the high-salinity waters below $20 \mathrm{~m}$ were almost as warm as the low-salinity waters above, the mixed-layer depth (MLD) decreased more rapidly than isothermal-layer depth (ILD), leading to a barrier layer $20 \mathrm{~m}$ thick. There was no rainfall in situ, as seen from shipboard measurements (figure 10), implying that the low-salinity surface waters were advected from elsewhere; the high-salinity waters below were also advected to the TSL. Thus, the WICC, which normally advects high-salinity waters equatorward during the summer monsoon, can also at times, advect a thin layer $(\sim 20 \mathrm{~m})$ of low-salinity waters that are formed at the surface as a result of rainfall or river runoff. The $0.2 \mathrm{PSU}$ decrease over $20 \mathrm{~m}$ seen at TSL2 on 11 th July is equivalent to the decrease in salinity due to $\mathrm{a} \sim 12 \mathrm{~cm}$ local rain event.

During SK-179, there was a heavy rainfall event measured on board during 1st-4th August (figure 10), when there was a similar event on land (Mohanty et al 2002). MLD decreased as a result and ILD increased owing to the increase in wind speed (figure 10). The decrease in MLD was particularly rapid early on 4th August, and a $\sim 40 \mathrm{~m}$ thick barrier layer formed. It disappeared however, within 10 hours. There was a 0.7 PSU decrease in salinity over the top $10 \mathrm{~m}$ during this event, even though the in situ rainfall of $\sim 10 \mathrm{~cm}$ could have caused a decrease of only 0.35 PSU. Hence, advection of low-salinity waters in the near-surface layer was again important. The contour of low salinities (figure 7) deepened over a few hours during 3rd-4th August, forming the hypotenuse of a right triangle and suggesting vertical mixing of the rainwater coupled with advection (figure 7). The disappearance of the low salinities, however, was instantaneous over their entire depth range; this can only be effected by advection away from the TSL of the low-salinity waters. The salinity recovered rapidly, but decreased again late on 4th August. This is also due to advection of low-salinity waters. The decrease was $\sim 0.2 \mathrm{PSU}$ over the top $20 \mathrm{~m}$, equivalent to the effect of $\sim 12 \mathrm{~cm}$ of in situ rainfall.

Thus, the WICC, by advecting both high-salinity waters and low-salinity pools that form as a consequence of rainfall over the sea and of river runoff, plays a role in the mixed-layer physics of the EAS. The low-salinity pools are advected with the current and mix slowly as they migrate. Hence, the effect of rainfall over the EAS or over the Indian west coast is not localised: a barrier layer may form at one location, but will be advected away from the source region. Since the mean WICC during the summer monsoon is equatorward, the effect of rainfall in the region will be felt more towards the southern part of the west coast. Hence, the impact of salinity on mixed-layer depth off the Indian west coast is significant in the south during the summer 

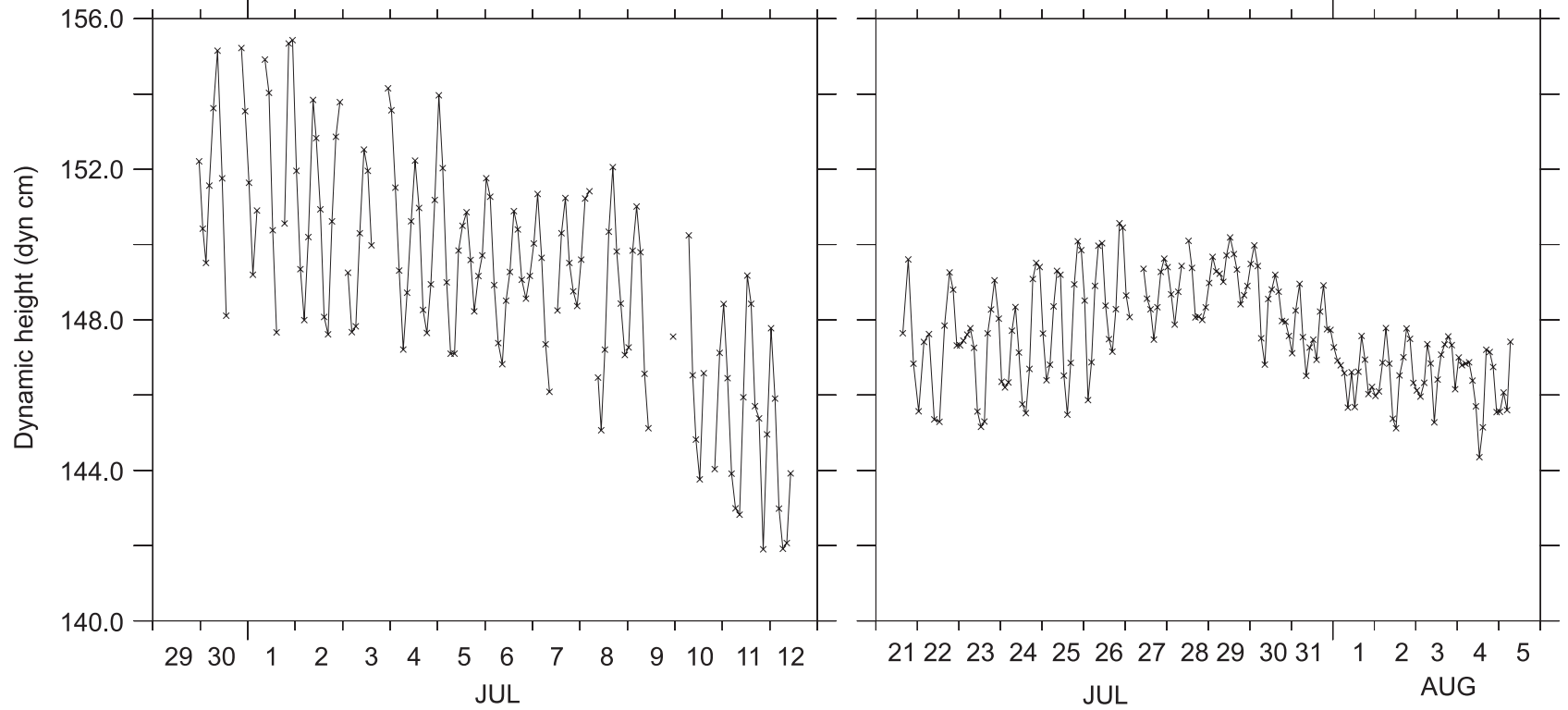

Figure 9. 0/1000 dbar dynamic height (dyn $\mathrm{cm}$ ) during the SK-178 (left) and SK-179 (right) time series.

monsoon, but not in the north (Rao and Sivakumar 2003).

There was, however, no discernible effect of these barrier layers on SST (figure 10), unlike in the Lakshadweep Sea before the onset of the summer monsoon (Durand et al 2004; Shenoi et al 2004, 2005a; Shankar et al 2004). The $10 \mathrm{~cm}$ rain event during SK-179 caused but a $0.2^{\circ} \mathrm{C}$ fall in temperature, comparable to the diurnal oscillation. Even this drop appears as a blip on the near-continuous drop in SST after 1st August, disappearing within hours owing to the advection of the low-salinity waters away from the TSL. The more systematic decrease after 1st August is due to the increase in wind speed. The reason for this lack of change in SST, in spite of significant changes in salinity, is that the barrier layer is ephemeral at any location: it does not remain at a given location long enough for its effect to be felt on SST.

\section{Water masses}

Evident in the TS diagrams for the two time series (figure 11) are the Arabian Sea High Salinity Water (ASHSW, $\sim 23-24 \sigma_{t}$ ) (Rochford 1964), the Arabian Sea Salinity Minimum (ASSM, 25.5$26 \sigma_{t}$ ) (Shenoi et al 1993; Shetye et al 1994), PGW $\left(\sim 26.2-26.8 \sigma_{t}\right)$, and RSW $\left(\sim 27-27.4 \sigma_{t}\right)$ (Rochford 1964). Among the most striking signals in the time series during both cruises is the intermittency in the salinity over practically the entire depth range (figures 5 and 7 ); this intermittency was also seen in the time series measurements in the Lakshadweep Sea during the second phase of ARMEX (March-June 2003) (Shenoi et al 2005b).

The uppermost salinity maximum, due to the ASHSW, appeared as a double maximum at both TSLs and at the northern stations in the alongshore sections during SK-179 (figure 12). South of about $13.5^{\circ} \mathrm{N}$, the ASHSW appeared as a subsurface maximum because of the presence of lowsalinity Bay of Bengal Water (BBW) at the surface (Kumar and Prasad 1999; Shenoi et al 2005b). The ASHSW signal was stronger in August than in June (figure 13), when it appeared in section G as a subsurface water mass owing to the low salinities at the surface (see sections 2 and 3 ). The equatorward advection of high-salinity waters from the north by the WICC gradually eliminates the low salinities at the surface and increases the salinity of the sub-surface ASHSW.

The salinity minimum (ASSM) (Shenoi et al 1993; Shetye et al 1994) was also more pronounced in the south; its strength weakens north of $14^{\circ} \mathrm{N}$ (figure 12). There was a sharp decrease in the strength of the salinity minimum at the station farthest from the coast in section G between June and August (figure 13), but the cross-shore variation was small. The ASSM disappeared at the SK-179 TSL after 30th July (figures 7 and 11).

The two high-salinity water masses below $200 \mathrm{~m}$, the PGW and the RSW, were generally distinct, but appeared at times as a single, mixed water mass (ASW) (figures 7, 11, and 13). The concentration of PGW did not show much crossshore variation, but that of RSW did: it was more concentrated on the continental slope and 

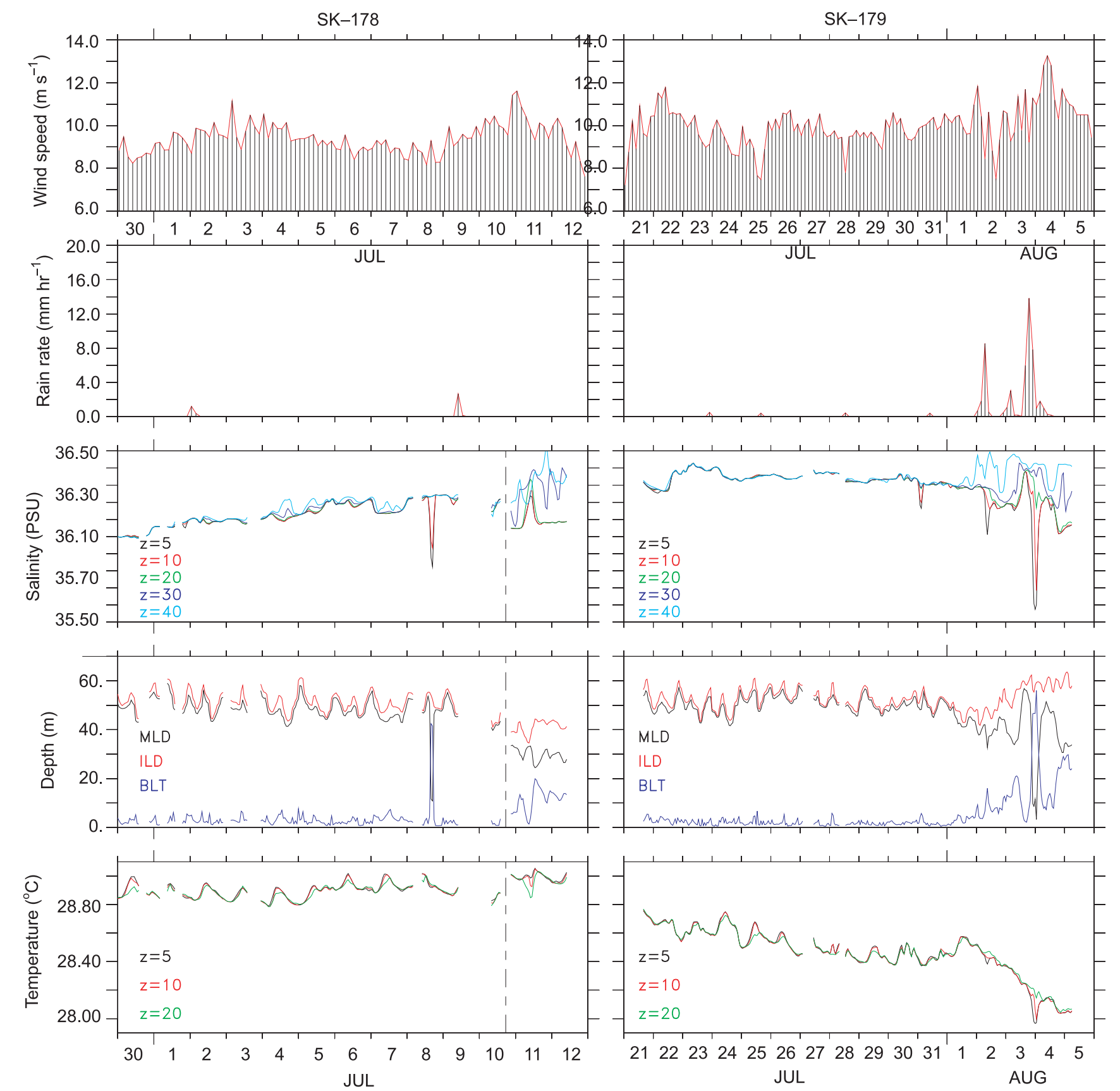

Figure 10. Wind speed (top panel, $\mathrm{m} \mathrm{s}^{-1}$ ), rain rate (second panel, $\mathrm{mm} \mathrm{hr}^{-1}$ ), salinity in the top $40 \mathrm{~m}$ (third panel, PSU), mixed-layer depth (MLD, m), isothermal-layer depth (ILD, m), barrier-layer thickness (BLT, m) (fourth panel), and temperature in the top $20 \mathrm{~m} \mathrm{(}{ }^{\circ} \mathrm{C}$, bottom panel) during the SK-178 (left) and SK-179 (right) time series. The wind speed and rain rate were measured on board ORV Sagar Kanya at 10-minute intervals, but have been averaged over 3 and 2 hours respectively in the figure. The dashed line in the last three panels on the left separates the two time series during SK-178; this line is not shown in the top two panels because wind and rain measurements were continuous. In the fourth panel, the abbreviations used are as follows: MLD, Mixed Layer Depth; ILD, Isothermal Layer Depth; and BLT, Barrier Layer Thickness. BLT $=$ ILD - MLD.

the signal decayed offshore (figure 13). The coastward increase in salinity at the RSW $\sigma_{t}$ during the SK-178 time series (figure 5) was more pronounced on the slope. This can be seen from the TS diagrams for the two squares around the SK178 TSLs (figure 1); these were covered just before and after the time series. There was a 'burst' of
RSW at the $27 \sigma_{t}$ at the vertices of the square near the coast (NE and SE), and the burst was more prominent at the northern vertex, NE (figure 14). The concentration of RSW was less at the offshore vertices in the second occupation of the square. These observations have two implications. First, the water mass could not have been advected 

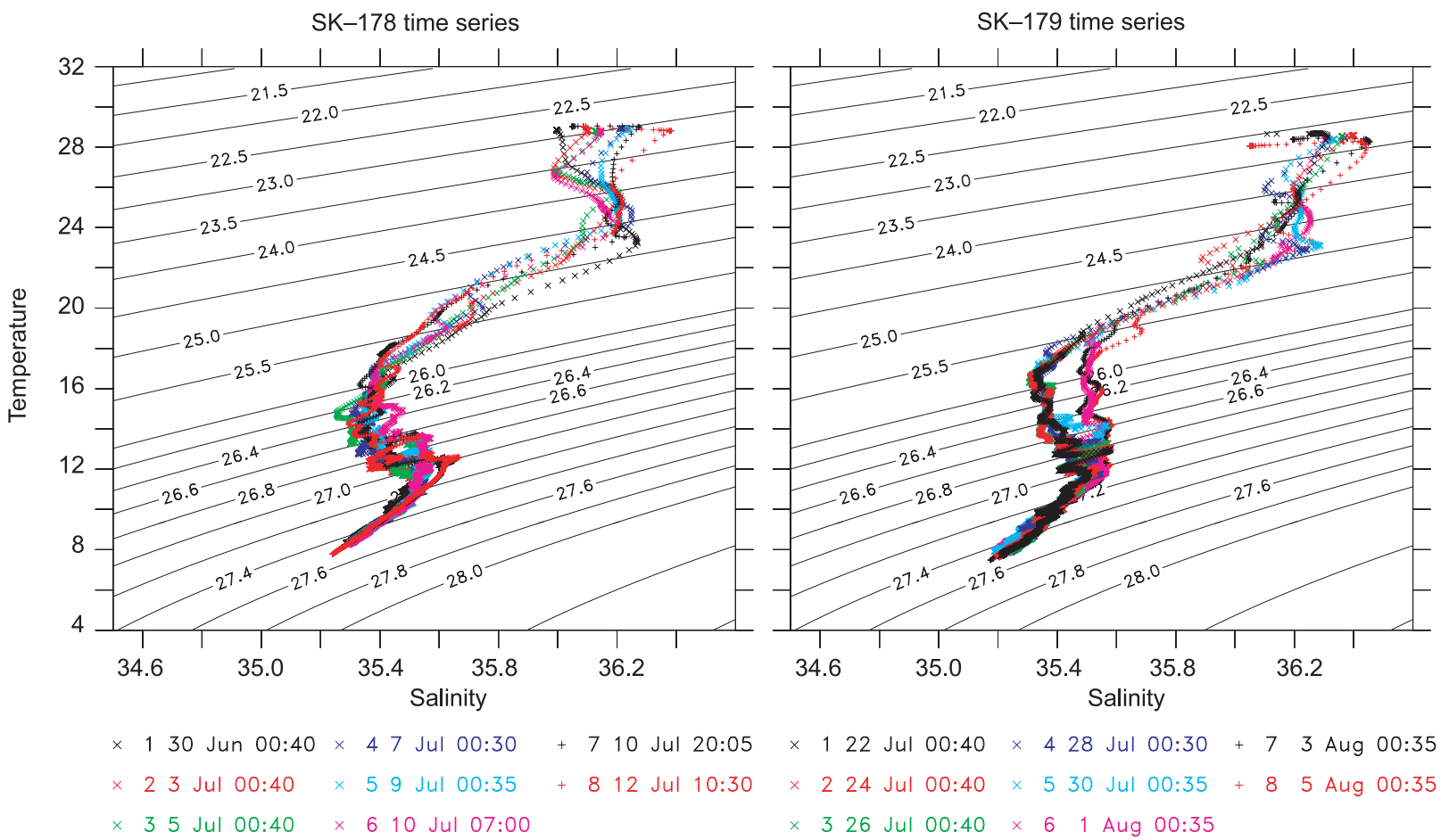

Figure 11. TS (temperature-salinity) diagrams for the SK-178 (left) and SK-179 (right) time series; temperature is in ${ }^{\circ} \mathrm{C}$ and salinity in PSU. The contours are of $\sigma_{t}\left(\mathrm{~kg} \mathrm{~m}^{-3}\right)$; note that the contour intervals are not uniform. The identification number (1-8) in the legend refers to the numbers at the top of the temperature and salinity plots for the time series (figures 5 and 7 ). Note that the SK-178 time series was at two locations TSL1 and TSL2 and the switch was made between TS curves 7 and 8 .

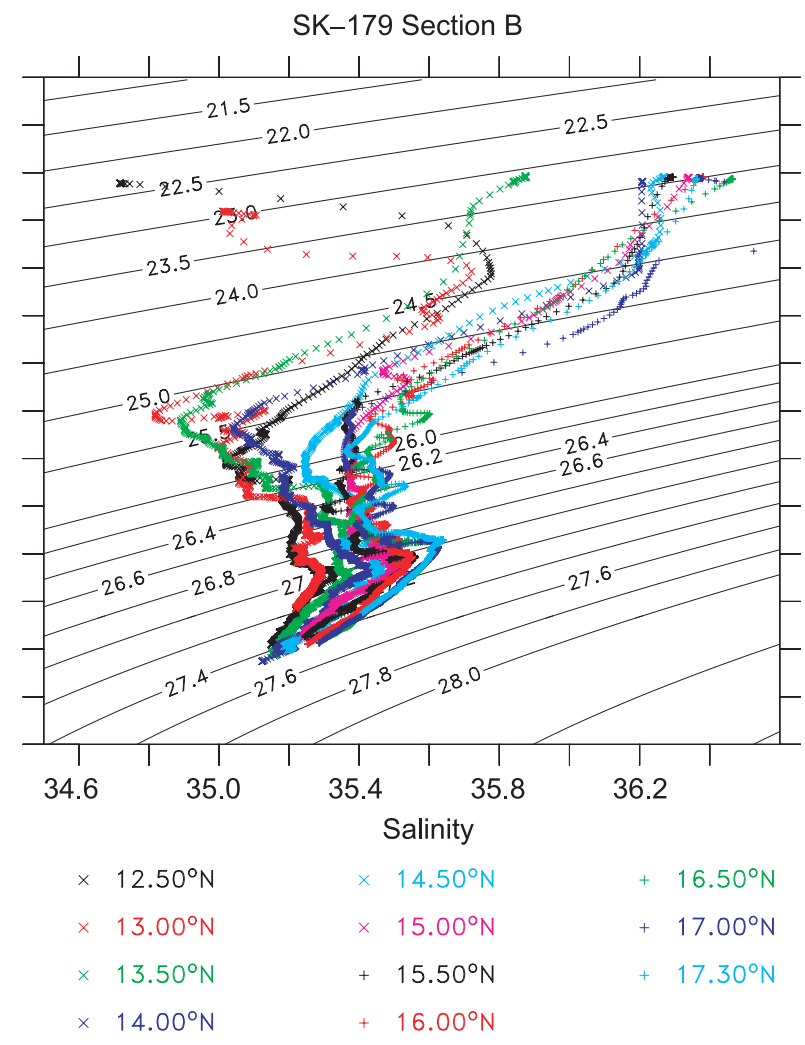

Figure 12. TS diagram for the alongshore section B during SK-179. The station locations in the legend are marked at the top of the temperature and salinity plots for the section (figure 4). from offshore to the square, and second, the water mass must have come from north of the SK-178 TSL. The alongshore sections also show that the concentration of PGW and RSW was greater in the north, but both water masses were present also at $12.5^{\circ} \mathrm{N}$ (figure 12) and even farther south (Shenoi et al 2005b). Though no observation was made north of $17^{\circ} \mathrm{N}$ during these two cruises, earlier literature suggests that the RSW is not found north of $17^{\circ} \mathrm{N}$ along the Indian west coast (Varma et al 1980; Babu et al 1980; Shenoi et al 1993). An alongshore section constructed from unpublished data from a cruise off the Indian west coast during March-April 1994 (cruise SS118 of FORV Sagar Sampada) shows, however, that RSW exists on the continental slope even in the northernmost sections $\mathrm{G}$ and $\mathrm{H}\left(\sim 22^{\circ} \mathrm{N}\right)$, which coincide with sections $\mathrm{K}$ and $\mathrm{M}$ in Shetye et al (1990, 1991). As one goes poleward, however, it is difficult at times to distinguish the RSW from the PGW (as in the SK-179 time series after 28th July). The strong PGW signal in the northern Arabian Sea makes it difficult to discern the presence of the RSW (Morrison 1997).

An implication of the coastward (on the slope) and poleward increase in RSW concentration along the entire Indian west coast (see also the section in Shenoi et al 2005b) is that along this coast, the RSW is advected from north to south; this was 

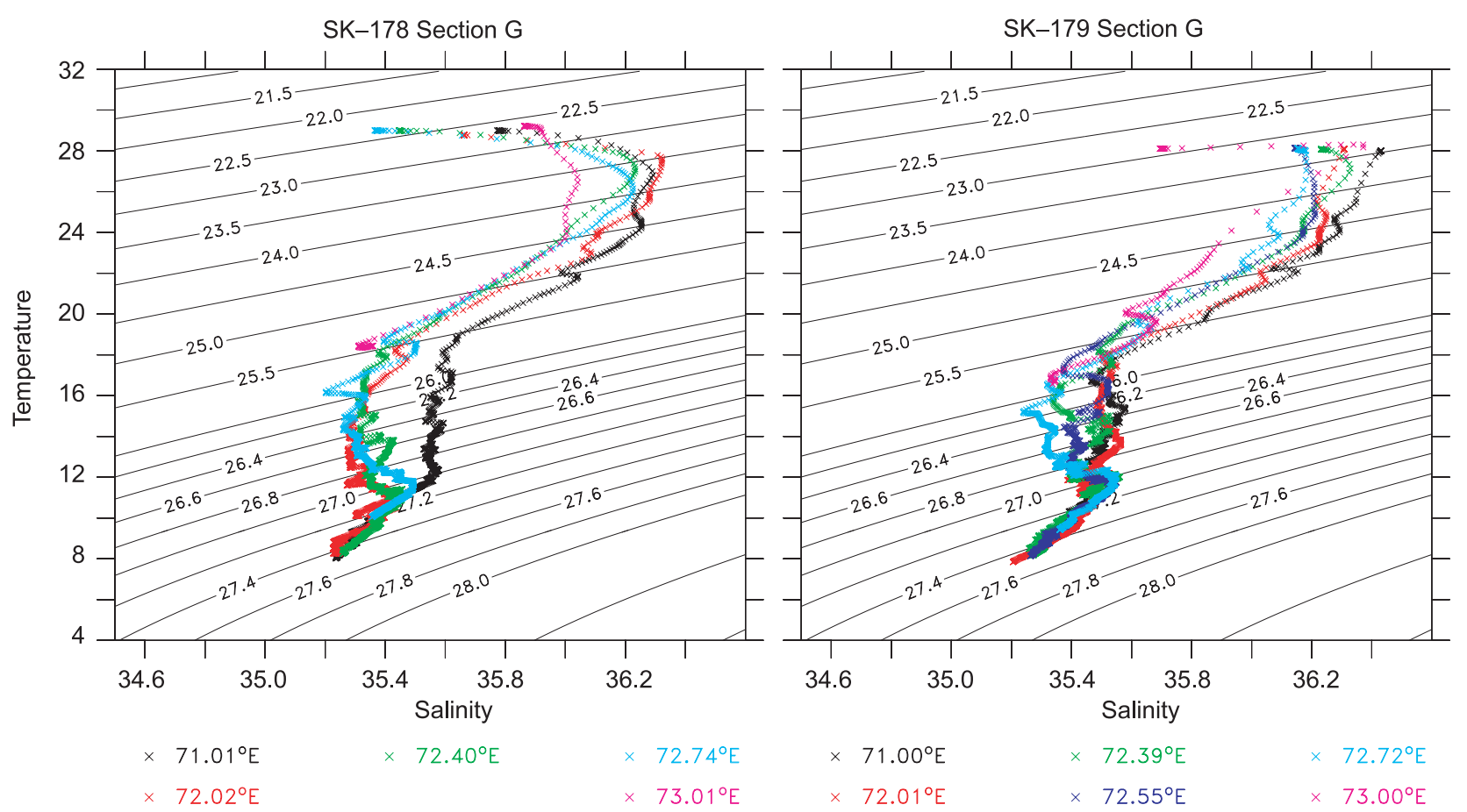

Figure 13. TS diagrams for section G during SK-178 (left) and SK-179 (right). The station locations in the legend are marked at the top of the temperature and salinity plots for the two sections (figures 2 and 3 ).
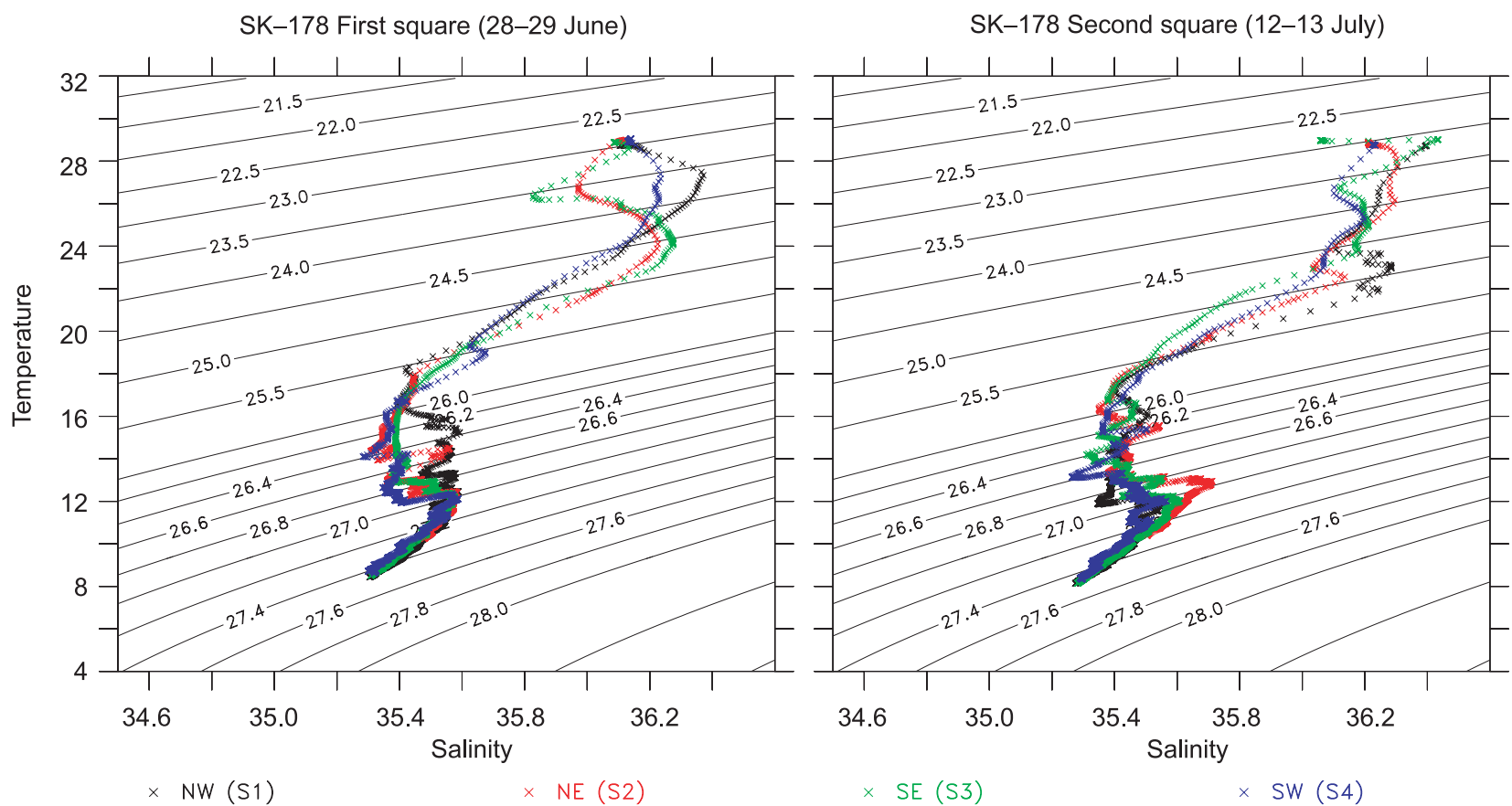

Figure 14. TS diagrams for the squares around the SK-178 TSLs. The diagram on the left (right) is for the first (second) occupation of the square, which was before (after) the time series. The vertices are as follows. NW (S1) is the northern of the two vertices on the side farther from the coast, NE (S2) and SE (S3) the northern and southern vertices on the side nearer the coast, and SW the southern of the two vertices on the side farther from the coast. The tags in parentheses refer to the cast numbers in the cruise report.

suggested by Babu et al (1980) on the basis of bottle-cast data from one alongshore section along the $1000 \mathrm{~m}$ isobath. That the RSW concentration increases coastward along the west coast implies that the RSW must reach it from farther north, not from the west. 


\section{Discussion}

We have described the hydrography of the eastern Arabian Sea (EAS) as observed in two cruises during June-August 2002. The main purpose of this paper was to present the hydrographic data.

An ephemeral barrier layer formed below the surface mixed layer near $17^{\circ} \mathrm{N}$ in early July and near $15.5^{\circ} \mathrm{N}$ in late July. This was owing to both in situ rainfall and advection, the latter appearing as a more prominent cause. The WICC normally advects high-salinity surface waters equatorward during the summer monsoon. It also advects, however, the low-salinity pools that form as a consequence of rainfall over the EAS and river runoff. The low-salinity pools mix slowly as they migrate. Hence, the effect of rainfall over the EAS or over the Indian west coast is not localised: a barrier layer may form at one location, but will be advected away from the source region. Since the mean WICC during the summer monsoon is equatorward, the effect of rainfall in the region will be felt more towards the southern part of the west coast. There was no discernible effect of these ephemeral barrier layers on SST, unlike in the Lakshadweep Sea before the onset of the summer monsoon (Durand et al 2004; Shenoi et al 2004, 2005a).

Variability in the salinity field was not confined to the surface layers, but was evident throughout the depth range of the observations. The highsalinity water masses (ASHSW, PGW, and RSW) and the salinity minimum (ASSM) were not always present, but appeared and disappeared during the time series. This is not surprising because RSW at least is known to occur even in the northwestern Arabian Sea as filaments or lenses (Shapiro et al 1994). The salinity of the ASHSW, PGW, and RSW decreased equatorward, as has also been noted earlier (Babu et al 1980; Shenoi et al 1993), and that of the RSW also decreased offshore. This implies that the RSW moves from north to south along the Indian west coast.

This intermittency, and the fact that the watermass layers are often thin (see, for example, the PGW and RSW signals in the first half of the SK179 time series in figure 7), has implications. As also noted during other ARMEX time-series measurements (Shenoi et al 2005b), the earlier technology of sampling with bottles was very likely to miss the signal because the water samples were collected only at certain depths. Hence, the $20-40 \mathrm{~m}$ thick cores of the PGW or RSW between 200 and $700 \mathrm{~m}$, where water samples were collected usually at intervals of over $100 \mathrm{~m}$, would have missed the signal, and this is the likely reason for the noted 'absence' of the PGW along the Indian west coast during the summer monsoon (Shenoi et al
1993; Prasad et al 2001). Another salinity signal that needed CTD measurements for its elucidation is the interleaving of high and low-salinity layers where the high-salinity ASHSW and low-salinity BBW mix; these interleaved layers are also as thin as $20 \mathrm{~m}$ (see figures 5 and 7 ) and are subject to considerable vertical movement owing to internal tides.

Is this sampling problem and the difficulty in distinguishing the strong PGW signal from the relatively weaker RSW signal in the northern Arabian Sea also responsible for the noted absence of RSW there (Sastry and D'Souza 1972; Varma et al 1980; Shenoi et al 1993)? This question is important if the RSW moves equatorward along the Indian west coast and its concentration decreases offshore along the coast. How does the RSW reach the Indian coast? There seem to be two possible routes. One route is coastal, i.e., it moves poleward from the Gulf of Aden along the continental slope off Oman, then westward along the slopes off Iran and Pakistan to the slope off India. The other route is via a deep monsoon current (for a description of the upper layers of the monsoon currents, see Shankar et al 2002), which does not hug the coast but flows across the basin in the northern Arabian Sea; this deep, cross-basin flow can connect to the Indian west coast at its northern end. There have been suggestions that RSW spreads eastward into the Arabian Sea during the summer monsoon (Gamsakhurdiya et al 1991; Beal et al 2003), but the observations are inconclusive because the RSW in the interior of the basin occurs in patches (Beal et al 2000). High-resolution CTD observations on the continental slopes off Pakistan and Iran and high-resolution model simulations are needed to answer this question. Note that ARGO floats may also miss the RSW signal because the normal sampling interval increases to almost $50 \mathrm{~m}$ at the RSW depths; if they are to be used to study the movement of such thin water-mass layers, the floats will have to be programmed to sample at finer intervals over the entire depth range.

In conclusion, we note that even though the ARMEX cruises described here were designed to study IREs, implying a focus on the atmospheric observations, the CTD time-series measurements will help reinterpret some of the earlier hydrographic observations.

\section{Acknowledgements}

A national programme like ARMEX would not have been possible without the support and cooperation of several groups. We thank them all. We thank the Department of Science and Technology (DST) and the Department of Ocean Development 
for financial support, DST's "Working Group on Ocean-Atmosphere Field Experiments under ICRP" and Satish Shetye for guidance during the field programme, the masters, crew, and supporting engineers on board ORV Sagar Kanya for rendering considerable assistance during the cruises, and the other cruise participants for their support. The wind and rainfall data from ship-borne measurements were made available by G S Bhat and the TMI data were downloaded from ftp://ftp.ssmi.com. We thank F Durand for useful discussions and K Banse and an anonymous reviewer for their comments, which helped us focus the manuscript and improve it. Pramila Gawas helped with figure 1; the software packages Ferret and GMT were used extensively. The harmonic analysis for internal tides was done using the package TASK. This is NIO contribution 3978 .

\section{References}

Anonymous 1996 TASK: Tidal Analysis Software Kit, Proudman Oceanographic Laboratory, Bidston, UK.

Anonymous 2001 Arabian Sea Monsoon Experiment (ARMEX): Science plan, Department of Science and Technology, New Delhi.

Anonymous 2002 Arabian Sea Monsoon Experiment (ARMEX): 1. Offshore Trough Experiment (Operations and implementations plan), Department of Science and Technology, New Delhi.

Antony M K 1990 Northward undercurrent along the west coast of India during upwelling - Some inferences; Indian J. Mar. Sci. 19 95-101.

Babu V R, Varkey M J, Das V K and Gouveia A D 1980 Water masses and general hydrography along the west coast of India during early March; Indian J. Mar. Sci. 9 82-89.

Banse K 1958 On upwelling and bottom trawling off the southwest coast of India; J. Mar. Biol. Ass. India 1 33-49.

Banse K 1968 Hydrography of the Arabian Sea Shelf of India and Pakistan and effects on demersal fishes; Deep-Sea Res. 15 45-79.

Beal L M, Ffield A and Gordon A L 2000 Spreading of Red Sea overflow waters in the Indian Ocean; J. Geophys. Res. 105 8549-8564.

Beal L M, Chereskin T K, Bryden H L and Ffield A 2003 Variability of water properties, heat and salt fluxes in the Arabian Sea, between the onset and wane of the 1995 southwest monsoon; Deep-Sea Res. II 50 2049-2075.

Bruce J G, Johnson D R and Kindle J C 1994 Evidence for eddy formation in the eastern Arabian Sea during the northeast monsoon; J. Geophys. Res. 99 7651-7664.

Durand F, Shetye S R, Vialard J, Shankar D, Shenoi S S C, Ethe C and Madec G 2004 Impact of temperature inversions on SST evolution in the southeastern Arabian Sea during the pre-summer monsoon season; Geophys. Res. Lett. 31 L01305 doi:10.1029/2003GL018906.

Foreman M G G 1977 Manual for tidal heights analysis and prediction, Pacific Marine Science Report, 78-6, Institute of Ocean Sciences, Canada.

Gadgil S, Srinivasan J, Nanjundiah R S, Krishnakumar K, Munot A and Rupakumar K 2002 On forecasting the
Indian summer monsoon: The intriguing summer of 2002; Curr. Sci. 83 394-403.

Gamsakhurdiya G R, Meschanov S L and Shapiro G K 1991 Seasonal variations in the distribution of Red Sea waters in the northwestern Indian Ocean; Oceanology 31 $32-37$.

Han W and McCreary J P 2001 Modeling salinity distributions in the Indian Ocean; J. Geophys. Res. 106 859-877.

Hareeshkumar P V, Mohankumar N and Radhakrishnan K G 1995 Multiple subsurface maxima in vertical salinity structure: A case study; Indian J. Mar. Sci. 24 $77-81$.

Johanessen O M, Subbaraju G and Blindheim J 1981 Seasonal variations of the oceanographic conditions off the southwest coast of India during 1971-1975; FiskDir Skr. Ser. HavUnders. 18 247-261.

Kalsi S R, Hatwar H R, Jayanthi N, Subramaniam S K, Shyamala B, Rajeevan M and Jenamani R K 2004 Various aspects of unusual behaviour of monsoon 2002, Ind. Met. Monograph No.: Synoptic Meteorology No. 2/2004, National Climate Centre, India Meteorological Department, New Delhi.

Kumar S P and Prasad T G 1999 Formation and spreading of Arabian Sea high-salinity water mass; J. Geophys. Res. 104 1455-1464.

Levitus S and Boyer T P 1994 World Ocean Atlas 1994: Temperature, NOAA Atlas NESDIS 4.

Levitus S, Burgett R and Boyer T P 1994 World Ocean Atlas 1994: Salinity, NOAA Atlas NESDIS 3.

McCreary J P, Kundu P K and Molinari R L 1993 A numerical investigation of the dynamics, thermodynamics and mixed-layer processes in the Indian Ocean; Prog. Oceanogr. 31 181-244.

Mohanty U C et al 2002 Weather summary during Arabian Sea Monsoon Experiment (ARMEX) 2002, I: Daily weather summary, heavy rainfall events and anomaly fields during 2002, Indian Institute of Technology, Delhi.

Morrison J M 1997 Inter-monsoonal changes in the T-S properties of the near-surface waters of the northern Arabian Sea; Geophys. Res. Lett. 24 2553-2556.

Prasad T G, Ikeda M and Kumar S P 2001 Seasonal spreading of Persian Gulf water mass in the Arabian Sea; J. Geophys. Res. 106 17,059-17,071.

Rao R R and Sivakumar R 2003 Seasonal variability of sea surface salinity and salt budget of the mixed layer of the north Indian Ocean; J. Geophys. Res. 1083009 doi:10.1029/2001JC000907.

Reynolds R and Smith T 1994 Improved global sea surface temperature analysis using optimum interpolation; J. Clim. 7 929-948.

Rochford D J 1964 Salinity maxima in the upper $1000 \mathrm{~m}$ of the north Indian Ocean; Austr. J. Mar. Freshw. Res. 15 $1-24$.

Sastry J S and D'Souza R S 1972 Oceanography of the Arabian Sea during the southwest monsoon - III: Salinity; Indian J. Met. Geophys. 23 479-490.

Shankar D and Shetye S R 1997 On the dynamics of the Lakshadweep high and low in the southeastern Arabian Sea; J. Geophys. Res. 102 12,551-12,562.

Shankar D, Vinayachandran P N and Unnikrishnan A S 2002 The monsoon currents in the north Indian Ocean; Prog. Oceanogr. 52 63-120.

Shankar D, Gopalakrishna V V, Shenoi S S C, Durand F, Shetye S R, Rajan C K, Johnson Z, Araligidad N and Michael G S 2004 Observational evidence for westward propagation of temperature inversions in the southeastern Arabian Sea; Geophys. Res. Lett. 31 L08305 doi:10.1029/2004GL019652. 
Shapiro G L, Meschanov S L and Polonsky A B 1994 Red Sea water lens formation in Arabian Sea; Oceanology 34 $26-31$.

Sharma G S 1968 Seasonal variation of some hydrographic properties of the shelf waters off the west coast of India; Bull. Nat. Inst. Sci. India 38 263-276.

Shenoi S S C, Shetye S R, Gouveia A D and Michael G S 1993 Salinity extrema in the Arabian Sea; In Monsoon biogeochemistry, Mitt. Geol.-Paläont. Inst. Univ. Hamburg, (eds) V Ittekkot and R R Nair, 76 37-49 SCOPE/UNEP Sonderband.

Shenoi S S C, Shankar D and Shetye S R 2004 Remote forcing annihilates barrier layer in southeastern Arabian Sea; Geophys. Res. Lett. L05307 doi:10.1029/ 2003GL019270.

Shenoi S S C, Shankar D, Gopalakrishna V V and Durand F 2005a Role of ocean in the genesis and annihilation of the core of the warm pool in the southeastern Arabian Sea; Mausam 56 147-168.

Shenoi S S C et al 2005b Hydrography and water masses in the southeastern Arabian Sea during March-June 2003; J. Earth Syst. Sci. 114, this issue.
Shetye S R, Gouveia A D, Shenoi S S C, Sundar D, Michael G S, Almeida A M and Santanam K 1990 Hydrography and circulation off the west coast of India during the southwest monsoon 1987; J. Mar. Res. 48 $359-378$

Shetye S R, Gouveia A D, Shenoi S S C, Michael G S, Sundar D, Almeida A M and Santanam K 1991 The coastal current off western India during the northeast monsoon; Deep-Sea Res. 38 1517-1529.

Shetye S R, Gouveia A D and Shenoi S S C 1994 Circulation and water masses of the Arabian Sea; Proc. Indian Acad. Sci. (Earth Planet. Sci.) 103 107-123 (Special issue: Biogeochemistry of the Arabian Sea).

Stramma L, Fischer J and Schott F 1996 The flow field off southwest India at $8 \mathrm{~N}$ during the southwest monsoon of August 1993; J. Mar. Res. 54 55-72.

Varma K K, Das V K and Gouveia A D 1980 Thermohaline structure and watermasses in the northern Arabian Sea during February-April; Indian J. Mar. Sci. 9 148-155.

Vinayachandran P N 2004 Summer cooling of the Arabian Sea during contrasting monsoons; Geophys. Res. Lett. 31 doi:10.1029/2004GL019961. 